\title{
EFFECT OF ENERGETICALLY MODIFIED FLY ASH ON THE DURABILITY PROPERTIES OF CEMENT MORTAR
}

\author{
L. Krishnaraj, Yeddula Bharath Simha Reddy ${ }^{*}$, N. Madhusudhan \\ and P.T. Ravichandran \\ Department of Civil Engineering, SRM University, Kattankulathur-603203, Tamil Nadu, India. \\ *E-mail : yeddula.bharath1993@gmail.com
}

\begin{abstract}
This paper explores the effect of Energetically Modified Fly Ash (EFA) on the durability properties of the EFA blended cement mortar. The mechanical, as well as durability properties of the EFA blended mortar, were studied. Mechanical properties were studied with the help of Compressive strength test results. Durability properties were analyzed by conducting Water Absorption Test, Sorptivity Test and Rapid Chloride Penetration Test (RCPT). Class $\mathrm{C}$ fly ash was used as Raw Fly Ash and Grinding of Raw fly ash in the ball mills was carried out for 2 hours to obtain Energetically Modified Fly Ash (EFA). The Ordinary Portland cement (OPC) was supplanted at 30\% and $50 \%$ rates with EFA respectively. The water binding ratio's taken for mix combinations with and without $1 \%$ superplasticizers were 0.4 and 0.55 respectively. Supplanting with Energetically Modified Fly Ash at $50 \%$ rate while adopting higher $\mathrm{w} / \mathrm{b}$ ratio reduced the compressive strength at 28 days age. Nevertheless, implementation of lower water to binder ratio with the help of superplasticizer would augment the durability properties of the pastes. The water absorption content diminishes with the proliferation of EFA content in the cement paste as finer EFA particles lead to a declination in permeable voids. Incorporation of EFA reduced the sorptivity values of cement paste to its "negligible" range ascribable to the reduction in pore space. The EFA specimens produced better opposition to chloride ion penetration compared to control paste. SEM analysis reveals that incorporating EFA in the mortar escalates the development of $\mathrm{C}-\mathrm{S}-\mathrm{H}$ gel by utilizing the $\mathrm{C}-\mathrm{H}$ content, leading to better mechanical and durable mortar. As a consequence, it is conceivable to manufacture concrete of abridged permeability through incorporating up to $50 \%$ fly ash without undermining its strength.

Keywords: Durability, Chloride ion penetration, Water absorption, Sorptivity, Ball milling, Fly Ash, SEM Analysis.

(c) RASĀYAN. All rights reserved
\end{abstract}

\section{INTRODUCTION}

Concrete being utmost consumed construction constituent in the present-day world. The concrete durability is noteworthy in extreme conditions for a longer administration life. The concrete exploits mammoth magnitude of naturally available resources by way of cement and aggregates. Cement manufacturing annihilates the huge energy and causes approximately seven percent of entire greenhouse gas discharge in the world ${ }^{1}$.

An industry by-product which was currently being utilized widely as a pozzolanic material in blended cement was fly ash. The amalgamation of fly ash in the cement composite enriches its performance in the durability aspect. The robust interfacial bond formed within the binder and the aggregates, as well as less permeable paste, can be attained from the utilization of fly ash. Fly ash incorporated concrete was, therefore, least vulnerable to the admittance of the harmful solutions. The utilization of the fine fly ash consequences in superior strength properties of the concrete than those with the raw fly ash was confirmed $^{2,3}$.

Various reports demonstrated that the injection of a high degree of fly ash in the concrete specimen displayed exceptional durability properties, for example, high resistance to the permeability of chloride ions etc. ${ }^{4}$ It was reported that the fly ash concrete yielded a superior outcome in the diffusion of chloride than control concrete ${ }^{5}$. It was observed that the sorptivity coefficient was reduced by maintaining water to binder ratio within the values of $0.25-0.40$ despite the fact that content of fly ash was as high as sixty percent of the entire binder mass ${ }^{6}$. 
The imperviousness to chloride infiltration of mortar is a standout amongst the most vital issues in relation to the durability of the structures. At the point when the chloride ion concentration in the concrete surpasses a specific threshold value, corrosion of reinforced steel starts ${ }^{7}$. It was, for the most part, acknowledged that amalgamation of the pozzolanic substance enhances the imperviousness to chloride infiltration and diminishes chloride-instigated corrosion of the steel reinforcement ${ }^{8,9}$.

The objective of this study is to replace the cement content by $50 \%$ in the cement mortar by Energetically Modified Fly Ash (EFA) and also to produce mortar more durable with the help of EFA. In this study, durability, and mechanical properties of EFA blended cement mortar were evaluated.

\section{EXPERIMENTAL}

\section{Raw materials}

The Ordinary Portland Cement 43 grade was used as a primary binder which is having specific gravity 3.15 , Blaine's Fineness $2630 \mathrm{~cm}^{2} / \mathrm{g}$. The Class C Fly Ash acquired from Neyveli Lignite Corporation, Neyveli, Tamil Nadu was utilized as fractional replacement of cement in the study. The RFA was ground for 2 hours to reduce its size and EFA is produced and no changes in the chemical composition were recorded. However, with respect to physical properties, the particle size decreased and Blaine's fineness increased to $3526 \mathrm{~cm}^{2} / \mathrm{g}$. Distilled water having the $\mathrm{pH}$ value as seven was used for mortar preparation and casting of specimens. Conforming to IS 650, three different grades (Grade I, II and III) of standard Ennore sand has been used as the fine aggregate for preparing standard mortar samples. Conplast SP 340 which was based on sulfonated naphthalene polymers was used as superplasticizers (SPL).

\section{Specimen Preparation and Testing}

In this study Mix design that adopted to attain mortar mixes with an akin flow of $110 \pm 5 \%$ consistent with IS 5512. The adopted mix ratio for the mortar mix was $1: 2.75$. The water binding ratio's taken for mix combinations with and without $1 \%$ superplasticizers were 0.4 and 0.55 respectively.

For compression strength test, Water absorption test and Sorptivity test, the casting of $50 \mathrm{~mm}$ size cubes was used. And for RCP test, cylinders of $100 \times 200 \mathrm{~mm}$ dimensions were cast in conformity to ASTM C39. After 24 hours, de-moulding was done and samples were reserved in the water tank for curing up to the testing age.

Compression strength of the specimens was determined at 28 days of age as per ASTM C109 code specifications. The percentage of Water absorption of samples were measured as per ASTM C 1403. The sorptivity test was executed conferring to ASTM C 1585 code. For RCP test, after 28 days of curing the specimens were cut into fifty-millimetre portions, while the end portions were discarded and the test was carried out as described in ASTM C1202.

\section{Compressive Strength Test}

\section{RESULTS AND DISCUSSION}

Figure-1 shows the graphical illustration of the compressive strength of samples. The strength development of OPC mortar was rather good. It was found that replacement of cement with EFA by $50 \%$ reduces the strength of the mortar. When the water content was at $0.55,50 \%$ replacement of cement with EFA reduced by $13 \%$ compressive strength compared to control mortar. However, by reducing the water to binder ratio from 0.55 to 0.4 , the compressive strength was amplified. When water to binder ratio was kept at 0.4 , the compressive strength of specimens achieved the akin value as perceived for control mortar, this is primarily due to the decrease of voids in the mortar. The excess amount of water in the mortar will escape after the casting, this allows generating small voids inside the mortar. If the water content is low, the chance for void generation is less and hence the strength got increased.

\section{Water Absorption Test}

The percentage of water absorbed by the specimens at 28 days age were shown in Figure- 2 . It can be appreciated that at the 28 days age, the percentage of the absorption declines with the escalation in EFA 
content in the cement paste. This was owing to the characteristic that EFA is finer than cement particles which lead to a decline of permeable voids.

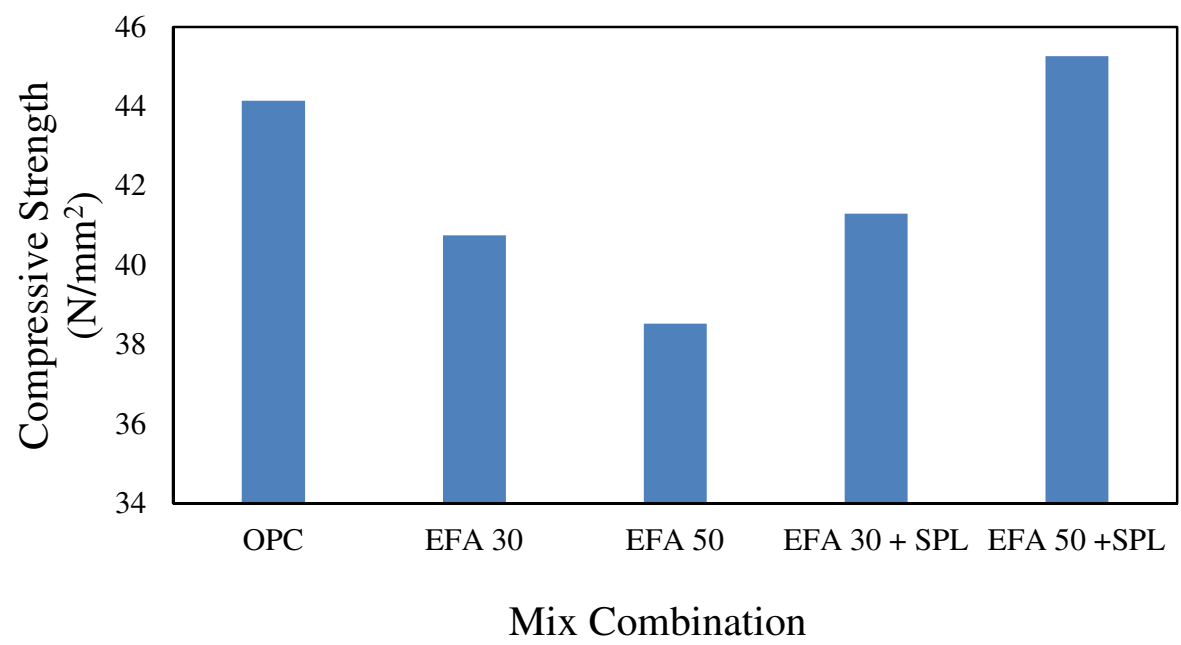

Fig.-1: Compressive Strength Test Results (28 Days)

It was further observed that specimens showed even lower water absorption when the water to binder ratio was reduced from 0.55 to 0.4 . As when the mortar has an excess amount of water content, this excess amount of water will evaporate from the mortar after casting. This space will remain as a void in the mortar allowing the water to occupy in those voids. That was the reason why the water absorption of mortars with $1 \%$ superplasticizer showed less value than the mortars without superplasticizer.



\section{Sorptivity Test}

Mix Combination

Fig.-2: Water Absorption Test Results (28 Days)

The sorptivity values were calculated for Energetically Modified Fly Ash blended mortar specimens at 28 days age were presented in Figure-3. It can be appreciated that sorptivity progressively declines with the rise in EFA content when compared with control mortar, this confirms that addition of EFA to the cement mortar leads to the decrease in the pore space. It was also perceived from the sorptivity statistics that mortar samples with superplasticizer showed the least value among all the specimens. 


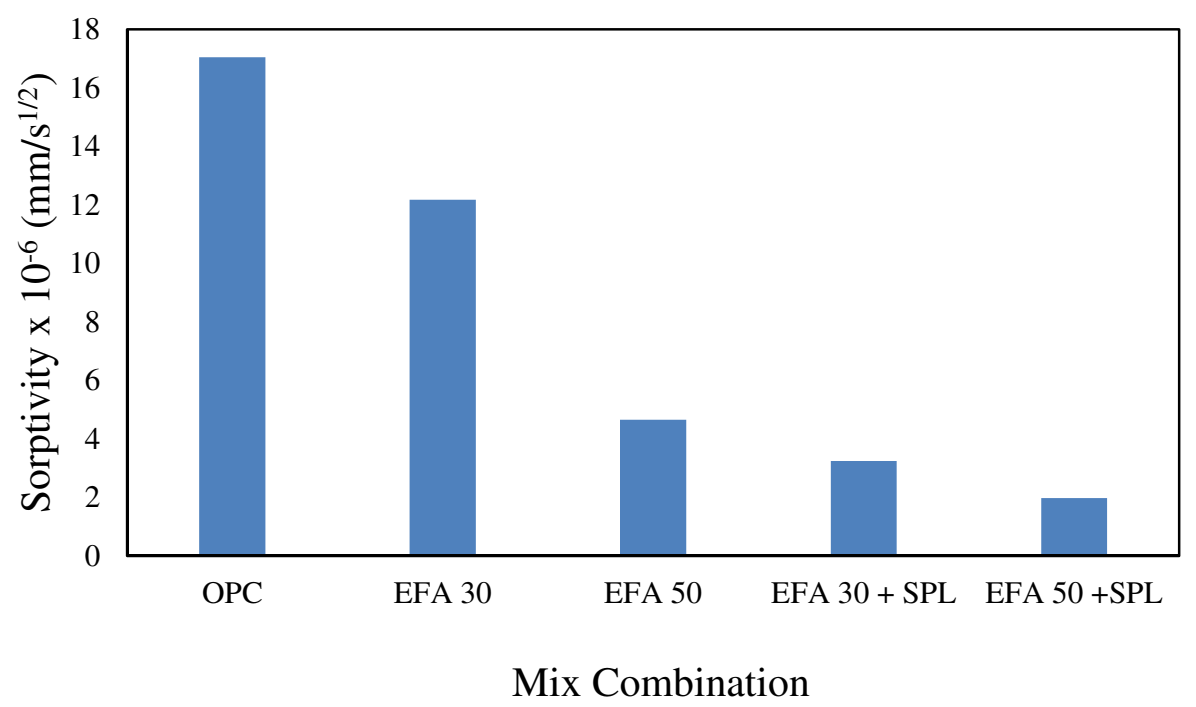

Fig.-3: Sorptivity Test Results (28 Days)

\section{Rapid Chloride Penetration Test (RCPT)}

The total charge (coulomb) delivered by the specimen in RCP test point out the penetration of chloride ions through it. The charge delivered by the samples of all the cement mortar mix combinations at the 28 days age were presented in Figure-4. The EFA blended cement pastes have shown better resistance compared to the conventional mix. Penetrability of chloride ions abridged with the rise of fly ash content in the mortar. At the 28 days age, fly ash pastes falls under 'Negligible' category of chloride ions penetration in contrast to the 'low level' of the control mortar as quoted in ASTM C1202 code. It was also witnessed that use of superplasticizers reduced the total charge passed to $95 \%$ compared to control mortar. It was noted that diminution in the water to binder ratio lessened the total charge passed through the specimen.

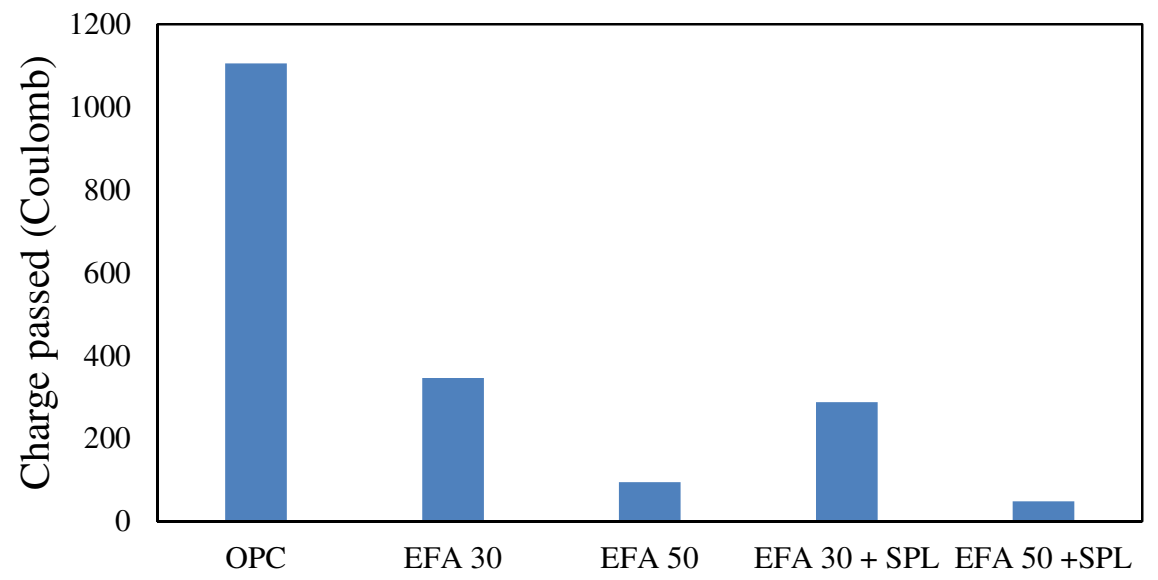

Mix Combinations

Fig.-4: Rapid Chloride Penetration Test Results (28 Days)

\section{Scanning Electron Microscope (SEM) Analysis}

SEM analysis results of control mortar and EFA mortar were shown in Figure-5a and 5b respectively at 28 days age. By incorporating EFA in the mortar, the formation of $\mathrm{C}-\mathrm{S}-\mathrm{H}$ gel was increased by consuming the $\mathrm{C}-\mathrm{H}$ content. This phenomenon points to the reduction in $\mathrm{Ca}(\mathrm{OH})_{2}$ crystals and filling up 
pore space with newly formed C-S-H compound leading to intensification of the bond between the cement materials and sand particles.

It was apparent from the SEM images that control mortar shows higher porous structure than the EFA mortar samples. Results indicate that incorporation of EFA enhanced the density and compact microstructure which was the reason for the upsurge in compressive strength in EFA mortar samples.

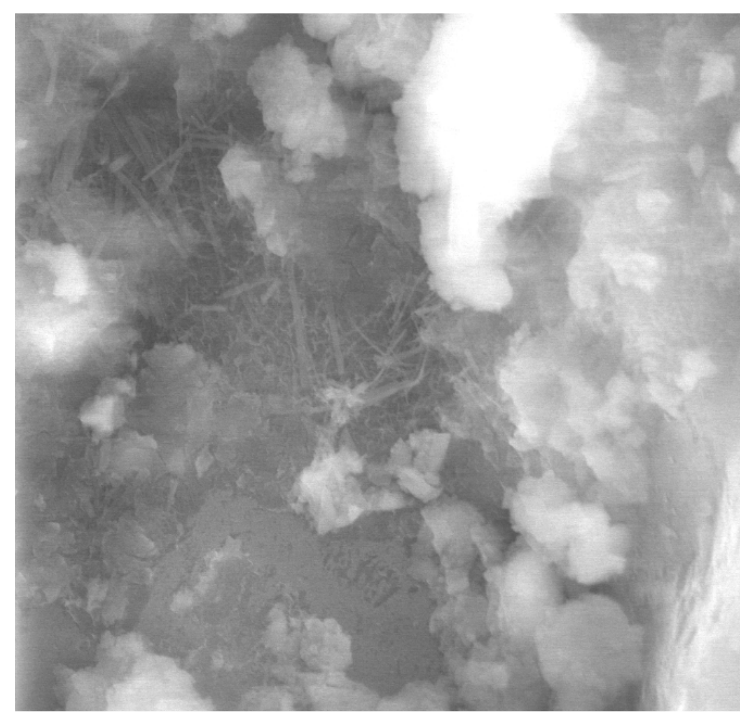

Fig.-5a: SEM image of Control mortar (28 Days)

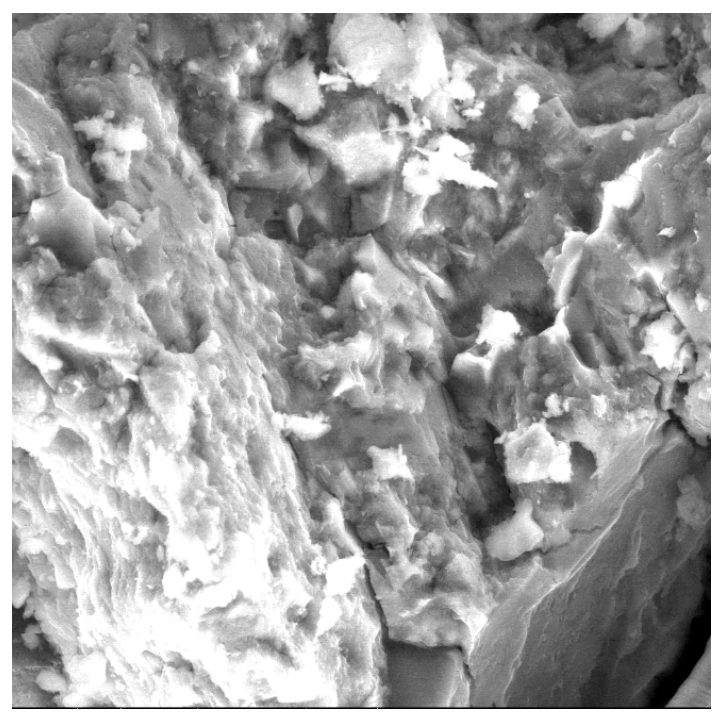

Fig.-5b: SEM image of EFA mortar with SPL (28 Days)

\section{CONCLUSION}

Five mixtures of cement composite pastes were considered to assess the outcome of thirty and fifty percent Energetically Modified Fly Ash (EFA) content on the durability properties of the mortar specimen at 28 days age. The subsequent deductions were drawn from the results:

1. Maintaining the water binder ratio at 0.55 and $50 \%$ replacement by Energetically Modified Fly Ash abridged the 28-day compressive strength of the mortar specimens. However, adoption of lower W/B ratio with the help of superplasticizer the compressive strength was amplified.

2. The water absorption percentage declines with the escalation in EFA content in the cement paste as finer EFA particles lead to a reduction of permeable voids. And also concluded that use of superplasticizers abridged the water absorption content.

3. Incorporation of EFA reduced the sorptivity values of cement paste to its "negligible" range ascribable to the reduction in pore space.

4. The EFA specimens produced better opposition to penetration of the chloride ion related to control paste. As a consequence, it is conceivable to manufacture concrete of abridged permeability by including up to $50 \%$ fly ash without undermining its strength.

5. Incorporating EFA in the mortar escalates the development of C-S-H gel by utilizing the C-H content, leading to better mechanical and durable mortar.

1. V.M. Malhotra, Concr. Int., 24, 30 (2012).

\section{REFERENCES}

2. K. Erdogdu, P. Turker, Cem. Concr. Res., 28, 1217 (1998).

3. P. Chindaprasirt, S. Homwuttiwong, V. Sirivivatnanon, Cem. Concr. Res., 34, 1087 (2004).

4. W. S. Langley, G. G. Carette, V. M. Malhotra, ACI Mater. J., 86, 507 (1989).

5. H. T. Cao, L. Bucea, E. Meek, S. Yozghatlian, CSIRO Report BRE., 30 (1996).

6. A. Camoes, B. Aguiar, S. Jalali, Int. Ash Util. Symp., University of Kentucky (2003).

7. M. Thomas, Cem. Concr. Res., 26(4), 513 (1996). 
8. C. Alonso, C. Andrade, M. Castellote, P. Castro, Cem. Concr. Res., 30(7), 1047 (2000).

9. M D. A.Thomas, P. B. Bamforth, Cem. Concr. Res., 29(4), 487 (1999).

10. Steve W. M. Supit, Faiz U. A. Shaikh, Constr. Build. Mater., 51, 278 (2013).

11. Jatuphon Tangpagasit, Raungrut Cheerarot, Chai jaturapitakkul, Kraiwood kiattikomol, Cem. Concr. Res., 35, 1145 (2005).

12. Kraiwood Kiattikomol, Chai Jaturapitakkul, Smith Songpiriyakij, Seksum Chutubtim, Cem. Concr. Compos., 23, 335 (2011).

13. Turhan Bilir, Osman Gencel, Ilker Bekir Topcu, Constr. Build. Mater., 93, 782 (2015).

14. M. R. Jones, A. McCarthy, A.P.P.G. Booth, Fuel, 85, 2250 (2005).

15. Gengying Li, Xiaozhong Wu, Cem. Concr. Res., 35, 1128 (2004).

16. C. Y. Lee, H. K. Lee, K. M. Lee, Cem. Concr. Res., 33, 425 (2002).

17. Liu Baoju, Xie Youjun, Zhou Shiqiong, Yuan Qianlain, Cem. Concr. Res., 30, 1489 (2000).

18. Md Emamul Haque, Int. J. Waste Resour., 3(1), 22 (2013).

19. M. Akram Tahir, Cem. Concr. Res., 33, 425 (2005).

20. Caijun Shi, Robert L. Day, Cem. Concr. Res., 25(1), 15 (1995).

21. En-Hua Yang, Yingzi Yang, Victor C. Li, ACI Mater. J., 104, 620 (2007).

22. Suresh Thokchom, Partha Ghosh, Somnath Ghosh, ARPN J. Eng. Appl. Sci., 4(7), 28 (2009).

23. R. Ramasubramani, R. Praveen, K. S. Sathyanarayanan, Rasayan J. Chem., 9(4), 706 (2016).

24. H. Akbar, G. Krishan, S. D. Prajapati, R. Saini, Rasayan J. Chem., 9(1), 27 (2016).

25. R. Gopalakrishnan, Rasayan J. Chem., 9 (3), 331 (2016).

[RJC-1682/2017] 